\title{
Recent applications of $X$-ray grating interferometry imaging to evaluate flame retardancy performance of brominated flame retardant
}

\author{
Mutairu B. Olatinwo ${ }^{1}$, Kyungmin $\mathrm{Ham}^{2}$, Jonathan McCarney ${ }^{3}$, Shashidhara Marathe ${ }^{4+}$, \\ Jinghua $\mathrm{Ge}^{5}$, Gerald Knapp ${ }^{6}$, and Leslie G. Butler ${ }^{1}$. \\ ${ }^{1}$ Department of Chemistry, Louisiana State University, 232 Choppin Hall, Baton Rouge, LA 70803, USA \\ ${ }^{2}$ Center for Advanced Microstructures \& Devices, Louisiana State University, 6980 Jefferson Highway, Baton \\ Rouge, LA 70806, USA \\ ${ }^{3}$ Albemarle Corporation, Process Development Center, P. O. Box 341, Baton Rouge, LA 70821, USA \\ ${ }^{4}$ Advanced Photon Source, Argonne National Laboratory, 9700 S. Cass Avenue, Argonne, IL 60439, USA \\ ${ }^{5}$ Center for Computation and Technology, Louisiana State University, 340 E Parker Blvd, Baton Rouge, LA \\ 70808, USA \\ ${ }^{6}$ Department of Mechanical and Industrial Engineering, Louisiana State University, Baton Rouge, LA 70803, \\ USA \\ ${ }^{+}$Division of Science, Diamond Light Source Ltd., Didcot, Oxfordshire, United Kingdom
}

\begin{abstract}
In this work, fire inhibition performance of four flame retardant formulations of brominated flame retardant (BFR: GreenArmor $\left.{ }^{\circledR}\right)$, antimony(III) oxide $\left(\mathrm{Sb}_{2} \mathrm{O}_{3}\right)$ and high impact polystyrene (HIPS) is reported. The standard Underwriters Laboratory (UL 94) vertical burn test was applied for assessing the flame retardancy of a variety of polymer blends. A formulation having $13.3 \mathrm{wt} \%$ GreenArmor ${ }^{\circledR}, 4 \mathrm{wt} \% \mathrm{Sb}_{2} \mathrm{O}_{3}$ and $82.7 \mathrm{wt} \%$ HIPS, named sample D, successfully passed the flame test and was rated $\mathrm{V}-0$. The other formulations with deficient composition exhibited low flame retardancy, as expected. The X-ray grating interferometry method is introduced for probing the 3D internal structures across the burnt UL 94 flame retarded polymer blend formulations to present the detailed mechanisms of flame retardancy. The X-ray images revealed several features for the formulation (sample D) that passed the UL 94 test: heat-induced dissolution of BFR and $\mathrm{Sb}_{2} \mathrm{O}_{3}$ residual particles, formation of gas bubbles inside the burnt polymer test bar, deflation of gas bubbles in a char layer through a microcrack, and thick char layer development, defined by the $\mathrm{Br}$ and $\mathrm{Sb}$ concentration profile to a depth of 100 to 220 microns. Also, the X-ray images show clear differences between formulations that pass and fail the UL 94 test. X-ray grating interferometry imaging is proposed as a novel technique for assessment of new generation flame retardants.
\end{abstract}

Key words: Brominated flame retardant; Single-shot checkerboard grating interferometry; X-ray K-edge absorption tomography; Underwriters Laboratories (UL 94) burn test.

Corresponding author:

Email: lbutler@1su.edu (Prof. Leslie G. Butler) 


\section{Introduction}

One of the newly developed, safe and more environmentally friendly brominated flame retardants (BFRs) is GreenArmor ${ }^{\circledR}$ [1], which is studied here with UL 94 and X-ray imaging in relation to blending (or homogeneity) and performance in a polymer matrix. The X-ray absorption imaging method is a very effective technique for visualization of 3D internal structures of materials in various fields, such as materials science [2-5], medical diagnostics, small-animal imaging and more [6-8]. It is highly valuable for high X-ray absorbing materials, but has a limitation of poor contrast for low X-ray absorbing materials such as polymers, biological tissues, and fiber composites $[6,7,9]$. To address this limitation of poor contrast, many phase sensitive imaging techniques, for example, X-ray grating interferometer, have been developed for phase sensitive X-ray imaging methods [6, 7, 9-12] to generate better contrast for low absorbing materials. This is because the generated phase shift values from X-ray interferometry are orders of magnitude larger than X-ray absorption values for low absorbing materials. The X-ray stepped-grating based interferometry method has been explored by Momose et al. [13] as a novel and simple imaging method for retrieving the phase shift as differential phase contrast (DPC) of phase sensitive samples. In 2005, Momose et al. [14] and Weitkamp et al. [6] demonstrated that X-ray grating-based interferometry was applicable to tomographic data acquisition (3D volumes).

Other researchers are studying alternatives to halogenated flame retardants for efficient and improved polymer additive properties with a variety of techniques. Prior works on nonbrominated flame retardant characterization have used laboratory X-ray tomography [1518], thermal conductivity [17], heat release rates and cone calorimeter [18, 19], pyrolysis gas chromatography, and SEM/EDX [20]. The present work with static X-ray K-edge tomography and static/dynamic X-ray interferometry is complementary. The K-edge tomography probes the chemical composition across the char layer as does EDX. The Kedge spatial resolution is poorer than EDX, but operates in 3D mode and without sample preparation. The K-edge imaging provides more sample detail-3D elemental mapping images - than conventional laboratory tomography which is mostly restricted to gas bubble analysis. The static X-ray interferometry yields a phase contrast image, like laboratory tomography, highlights gas bubble structure. X-ray interferometry also provides a dark-field image modality, which is closely related to small angle X-ray scattering. The dark-field image provides sub-pixel imaging for processes such as flame retardant grain dissolution. Particle dispersion analysis is a strength of SEM, prior and post burn, or when burning is terminated with liquid nitrogen [20]. A noteworthy advantage of X-ray interferometry is dynamic imaging of the burn process at imaging rates of a few Hertz [5], though the technology is just evolving and the imaging field of view is small relative to the combustion volume. X-ray single-shot grating interferometry is a recently developed imaging method that based on a Fourier analysis of harmonic images to generate absorption, differential phase contrast (DPC), and dark-field (or small-angle scattering) images [8, 21-25]. The small-angle scattering images allow structural examination at distance scales smaller than the pixel size of the imaging system $[8,26]$. Single-shot grating interferometry differs from the more common stepped-grating interferometry. Single-shot checkerboard grating interferometry does not require scanning in multiple directions or multiple images exposure 
to generate the three image modalities. Single-shot grating interferometry is suitable for small field of view 2D radiographic and 3D tomographic applications [27, 28].

The bromine composition in GreenArmor ${ }^{\circledR}$, Saytex ${ }^{\circledR}$ BT-93 [4] and Saytex ${ }^{\circledR} 8010$ [5] are 74, 63 and $82 \mathrm{wt} \%$ respectively. Here, these studies will focus on GreenArmor ${ }^{\circledR}$. The brominated flame retardant (BFR) gains effectiveness when used with a synergist, antimony(III) oxide $\left(\mathrm{Sb}_{2} \mathrm{O}_{3}\right)$ [29-31], in a $\mathrm{Br}: \mathrm{Sb}$ atom ratio of 3:1 [32]. The flame retardant process in GreenArmor ${ }^{\circledR}$ and other flame retardants is complex. The proposed action of mechanisms between BFR and $\mathrm{Sb}_{2} \mathrm{O}_{3}$ is based on their synergistic reaction of forming $\mathrm{SbBr}_{3}$ and $\mathrm{HBr}$ as free radical traps in the gaseous phase [33-35]. Sato et al. [36] and Ratna [37] also reported that effectiveness of flame retardant materials is due to the following mechanisms:

i. Dilution of combustible with non-combustible gases from flame retardant decomposition.

ii. Radical quenching by halogens released by the flame retardant.

iii. Reduced access to fuel due to formation of the char layer.

iv. Endothermic decomposition of flame retardant inhibits temperature rise.

The Underwriters Laboratories procedure (UL 94 vertical burn test) is applied to assess the flammability behavior of flame retardant polymer samples [38, 39]. Short burn time, selfflame suppression and absence of flaming polymer drips are good signs for successful flame retardants [38-40]. The UL 94 test is widely used by chemical companies and laboratories for testing flame retardant materials and products. However, new testing procedures are needed for the evaluation of flame retardants in new applications such as fused deposition modeling (3D printing). Herein, X-ray single-shot checkerboard grating interferometry and K-edge absorption tomography experiments are evaluated relative to the UL 94 test. The objective of this study is to enhance the traditional Underwriters Laboratory 94 burn test with X-ray imaging methods. While the UL 94 test is practical, it does not provide insight or $3 \mathrm{D}$ visualizations that can be readily applied to the evaluation of new flame retardants or the optimization of existing systems.

It is proposed that X-ray imaging techniques of post-burn samples reveal some of the mechanisms, or deficiencies encountered with non-optimal formulations. Two X-ray imaging methods are used herein on post-burn samples. First, the K-edge absorption imaging uses five to seven tomography data set volumes acquired at X-ray energies spanning $\mathrm{Br}(13.47 \mathrm{keV})$ and $\mathrm{Sb}(30.49 \mathrm{keV}) \mathrm{K}$-edges. The X-ray energies for K-edge tomography are 12, 15, 17, 25, 29 and $32 \mathrm{keV}$ depending on sample formulation. Second, single-shot X-ray interferometry/tomography is a novel method [28] used here on static, post-burn samples, but has the potential to acquire real-time images [5, 27] of a UL 94 test. The new X-ray optics used in this work have a limited field of view, restricting the application to static samples. The effective imaging results of GreenArmor ${ }^{\circledR}$ obtained herein with interferometry demonstrate the value of dark-field and differential phase contrast imaging, modalities that will be operative with light-element samples found in new generation of flame retardants. 
In this study, the formulated flame retardant polymer bars are burnt for initial flame retardancy assessment, and samples from the burnt polymer bars are studied with X-ray imaging methods. Three samples are intentionally formulated to be deficient in flame retardant and synergist, while the fourth formulation passes the UL 94 test. The test results and optical images are presented; the images show char layers and melt features, but not the internal structures. The X-ray single-shot checkerboard grating interferometry imagesabsorption, dark-field and differential phase contrast-show flame retardant dispersion, decomposition, and provide a visual indicator of the char layer. X-ray K-edge tomography yields $3 \mathrm{D}$ concentration volumes ( $\mathrm{vol} \%$ ) of $\mathrm{BFR}$ and $\mathrm{Sb}_{2} \mathrm{O}_{3}$ that provide a compositional indicator of the char layer. Histograms, line probes and 3D volume renderings of BFR and $\mathrm{Sb}_{2} \mathrm{O}_{3}$ concentration volumes are used to interpret the X-ray K-edge tomography data.

\section{Experimental}

\subsection{Materials}

The method of sample preparation was similar to previously reported work [5], except the studied BFR (GreenArmor ${ }^{\circledR}$ ) and $w t \%$. The samples were prepared at Albemarle Corporation by combining known weights of GreenArmor ${ }^{\circledR}, \mathrm{Sb}_{2} \mathrm{O}_{3}$, and high impact polystyrene (HIPS). Compounding was done in a ZSK $30 \mathrm{~mm}$ twin-screw extruder. A BOY 30A injection molding machine was used to mold the polymer test bars into the $12.5 \mathrm{~cm} \times$ $1.3 \mathrm{~cm} \times 0.32 \mathrm{~cm}(4.9 " \times 1 / 2 " \times 1 / 8 ")$ dimensions. With known weight and density of $\rho$ (HIPS $)=1.04 \mathrm{~g} / \mathrm{cm}^{3}, \rho\left(\mathrm{Sb}_{2} \mathrm{O}_{3}\right)=5.67 \mathrm{~g} / \mathrm{cm}^{3}$, and $\rho\left(\right.$ GreenArmor $\left.{ }^{\circledR}\right)=2.30 \mathrm{~g} / \mathrm{cm}^{3}$, formulation wt $\%$ was converted to vol\%. The sample formulations, both in $\mathrm{wt} \%$ and vol\% are given in Table 1 . The GreenArmor ${ }^{\circledR}$ density was calculated based on the procedure of Cao [41].

Table 1 Chemical Formulations and UL 94 Burn Test of Flame Retardant Polymer Samples.

\begin{tabular}{|c|c|c|c|c|c|}
\hline \multirow{2}{*}{$\begin{array}{l}\text { Components and } \\
\text { UL } 94 \text { burn test }\end{array}$} & \multicolumn{5}{|c|}{ Formulations in wt\%, [vol\%] } \\
\hline & A & $\mathrm{B}$ & $\mathrm{C}$ & & \\
\hline HIPS & $96,[99.24]$ & $86.75,[93.52]$ & $85.75,[93.26]$ & 82.75 & $92.46]$ \\
\hline BFR (GreenArmor ${ }^{\circledR}$ ) & $0,[0]$ & $13.30,[6.48]$ & $13.30,[6.54]$ & 13.3 & $6.72]$ \\
\hline $\mathrm{Sb}_{2} \mathrm{O}_{3}$ & $4,[0.76]$ & $0,[0]$ & $1.00,[0.200]$ & 4.00 & 0.82] \\
\hline T1 (s) & 27.86 & 52.27 & 78.59 & 0.96 & 0.83 \\
\hline $\mathrm{T} 2(\mathrm{~s})$ & 27.32 & 37.48 & 70.64 & 0.98 & 1.05 \\
\hline Average $(\mathrm{T} 1+\mathrm{T} 2)$ & 27.59 & 44.88 & 74.62 & 0.97 & 0.94 \\
\hline Classification & $\mathrm{V}-2$ & None & None & $\mathrm{V}-0$ & $\mathrm{~V}-0$ \\
\hline
\end{tabular}

$\mathrm{T} 1$ and T2 are the first and second times required to quench the flame. Samples B, C and D were formulated with the same wt $\%$ BFR, but showed slightly different calculated vol\% BFR as shown in Table 1. This showed the vol\% BFR increased with the amount of $\mathrm{Sb}_{2} \mathrm{O}_{3}$ added to the polymer formulation. The studied samples were cut from the burnt UL 94 polymer bars (A, B, C and D). For easy identification, the prime signs were used to name the single-shot X-ray interferometry samples (A', B', C' and D') while number integers were assigned for naming X-ray K-edge absorption tomography samples (A1, B1, C1, D1 and 
D2). Samples D1 and D2 were two cuts from different regions of the same burnt polymer bar, sample D.

\subsection{UL 94 vertical burn test}

A diagrammatic representation of the UL 94 burn test was shown in Fig. 1a. Prior to burn test, polymer bars were conditioned at $23{ }^{\circ} \mathrm{C}$ and $50 \%$ relative humidity at least $48 \mathrm{hrs}$. The UL 94 tests were performed at Albemarle Corporation using the UL 94 procedure [38] consisting of a calibrated methane flame and a vertically mounted polymer test bar in a chemical hood with suspended ventilation. Each sample was burned for $10 \mathrm{~s}$ with the methane flame, followed by flame removal. The time of self-flame suppression was noted. This procedure was repeated to calculate an average, and the tabulated results are shown in Table 1. Five polymer bars were tested for each sample. The flame retardancy classification of samples by the UL 94 test was based on burning time, and also the ignition of the underneath cotton by flaming drips. After the standard UL 94 test, samples were cut from the burnt polymer test bars to about $2.5 \mathrm{~mm}$ in cross-section and $4 \mathrm{~mm}$ long for X-ray Kedge absorption tomography studies and $1 \mathrm{~mm}$ in diameter for X-ray single-shot interferometry tomography. This difference in sample size was due to the imaging fields of view. The X-ray images and data were used for visualization and analysis of properties leading to good or poor polymer flame retardancy.

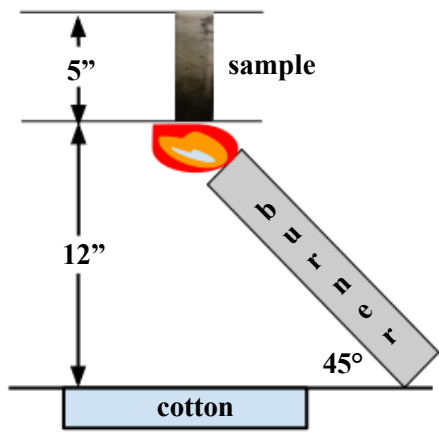

(a) UL 94 vertical burn test

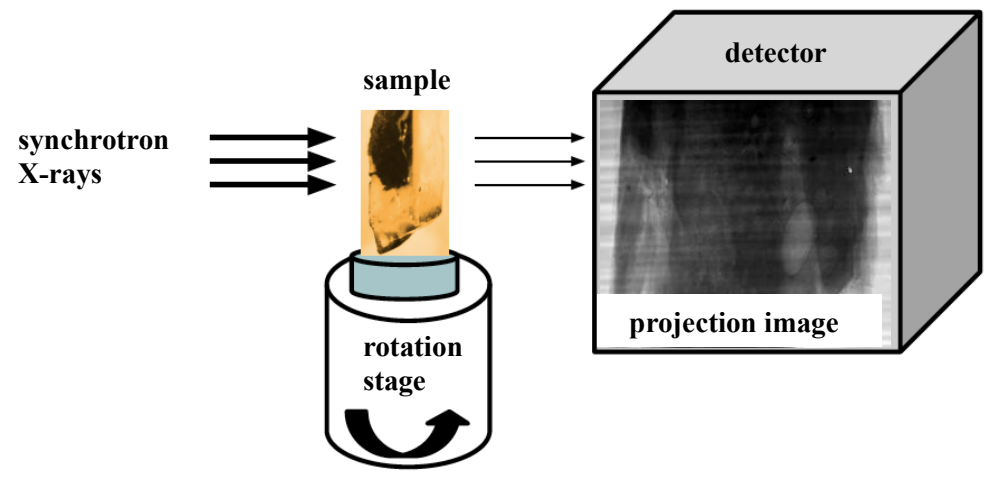

(b) X-ray K-edge synchrotron absorption tomography

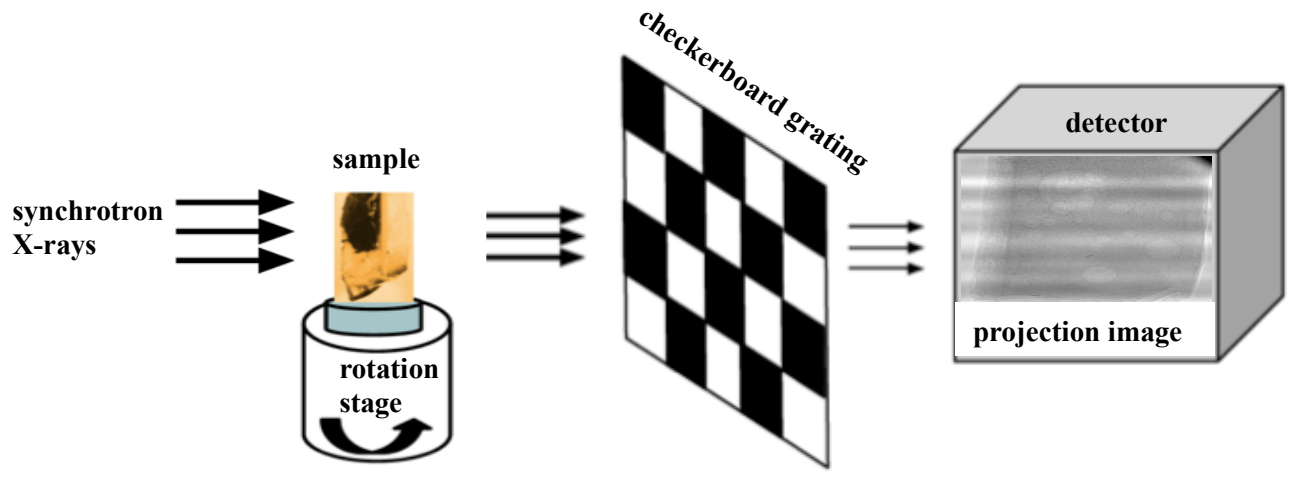

(c) X-ray single-shot grating based interferometry

Fig. 1. Schematic representation of (a) UL 94 vertical burn test; (b) X-ray synchrotron K-edge absorption tomography; and (c) X-ray single-shot grating based interferometry. 


\subsection{X-ray synchrotron K-edge tomography}

In the experiment shown Fig. 1b, the X-ray flux was generated at the synchrotron tomography beamline with a 7 Tesla wavelength shifter at the Louisiana State University Center for Advanced Microstructures and Devices. The beamline double multilayer monochromator was operated at 7 to $40 \mathrm{keV}$-typically $12,15,17,25,29$, and $32 \mathrm{keV}$ with a $3 \%$ bandpass. The tomography beam size at the sample was $1.3 \mathrm{~mm}$ high and $30 \mathrm{~mm}$ wide. For X-ray imaging, the sample was mounted on a goniometer located on a motor stack consisting of two tilt stages, a vertical translation stage, and a precision rotation stage. The distance between sample-to-scintillator was $10 \mathrm{~mm}$. The X-ray projection onto the $0.5 \mathrm{~mm}$ thick Ce:YAG scintillator (Marketech International) was imaged with a $45 \mathrm{~mm}$ working distance lens (Optique Peter) and a Princeton Instrument PIXIS 2KB CCD. The CCD pixel size was $13.5 \mu \mathrm{m}$; this, combined with the nominal $5.4 \times$ optical magnification, gave an effective pixel size of $2.5 \mu \mathrm{m}$. The exposure time was 2 seconds for a beam current of 120 $\mathrm{mA}$ at $12 \mathrm{keV}$. The typical field of view was $1500 \times 512$ pixels, corresponding to $3.75 \mathrm{~mm} \times$ $1.28 \mathrm{~mm}[5]$.

K-edge absorption tomography imaging was performed at sample rotation angles ranging from $0^{\circ}$ to $179.5^{\circ}$ with $0.5^{\circ}$ increment to acquire 360 projections of raw images. In addition to three X-ray-on reference images collected every $15^{\circ}$ during data acquisition, five X-rayoff images were taken at the beginning of the experiments for flat field correction. Projection reconstruction into absorption volumes was done with the Matlab filtered backprojection (FBP) code. Additional information is available in the previous article, particularly with regard to processing the six tomography volumes into BFR and $\mathrm{Sb}_{2} \mathrm{O}_{3} 3 \mathrm{D}$ volumes in units of vol\% concentration [5].

\subsection{X-ray synchrotron single-shot grating interferometry tomography}

The experiment in Fig. 1c shows the X-ray single-shot grating interferometer used for tomography data set acquisition at the Advanced Photon Source, 2-BM-B. Briefly, interferometry requires a phase coherent source such as a synchrotron as well as a phase optic and an evolution distance set by the Talbot effect. Also, a high resolution X-ray detector is needed to resolve the self-image of the phase optic [28, 42]. A checkerboard phase grating with a period of $4.8 \mu \mathrm{m}, \pi / 2$ phase shift at $22 \mathrm{keV}$ was mounted $306 \mathrm{~mm}$ upstream from the scintillator, which was the calculated Talbot distance using $\mathrm{np}^{2} / 2 \lambda$, where $\mathrm{n}$ is half-integer (1.5), $\mathrm{p}$ is the checkerboard grating period $(4.8 \mu \mathrm{m})$ and $\lambda$ is the X-ray wavelength $(0.0564 \mathrm{~nm})$. Image collection was performed with a LuAG:Ce scintillator of $10 \times$ optical magnification and a CoolSNAP K4 $2048 \times 2048$ CCD camera with $7.4 \mu \mathrm{m}$ pixels for an effective pixel size of $0.74 \mu \mathrm{m}$. During imaging, the exposure time was 0.55 seconds per projection. Projections were acquired from $0^{\circ}$ to $180^{\circ}$ by $0.12^{\circ}$ increments for a total of 1501 interferograms. For normalization, both reference images (images without a sample in the X-ray beam) and X-ray-off images were collected before the $0^{\circ}$ projection and after the $180^{\circ}$ projection. The Fourier-based procedure for processing the interferograms into absorption, differential phase contrast, and dark-field projections can be found in the previous work [5]. Projection reconstruction into volumes was done with ASTRA software using the SIRT reconstruction algorithm [43]. In the results section, the dark-field images 
are presented for scattering along the vertical direction; the DPC projections are shown along the horizontal direction.

\subsection{Development of a histogram analysis for dispersion}

The K-edge tomography work yields $3 \mathrm{D}$ volumes of $\mathrm{BFR}$ and $\mathrm{Sb}_{2} \mathrm{O}_{3}$ in volume percent units (vol\%), which are analyzed with average values, line probes, orthoslices, and histograms. This is a brief tutorial on the development and interpretation of histograms. First, the lumps visible in orthoslices are examined by drawing line probes across the lumps; this yields a vol\% threshold for observation of lumps within a matrix. It then becomes extremely important to determine what fraction of the component exists as lumps versus the fraction of component that is dispersed in the matrix at a distance scale below the imaging resolution. A histogram of vol\% is created with attention to the vol\% threshold for lumps.

Three hypothetical histograms are shown in Fig. 2 in relation to a 2 vol\% threshold for lump observation. All three samples have the identical average formulation of $1 \mathrm{vol} \%$ component and the same total voxel counts. One sample, Fig. 2a, is completely dispersed at the imaging resolution while the other two samples have observable lumps. The lumpiest sample, Fig. 2c, has a few voxels with 3 vol\% (shown in black) and many voxels with 0 vol\% of the component. The intermediate sample, Fig. $2 b$, has both a dispersed component (light grey) and some lumps (dark grey). Fig. $2 \mathrm{~b}$ is shown as bimodal, but a broad, single mode distribution can also support lumps. In these histograms, if a voxel is completely filled with the component, the abscissa will extend to $100 \mathrm{vol} \%$.
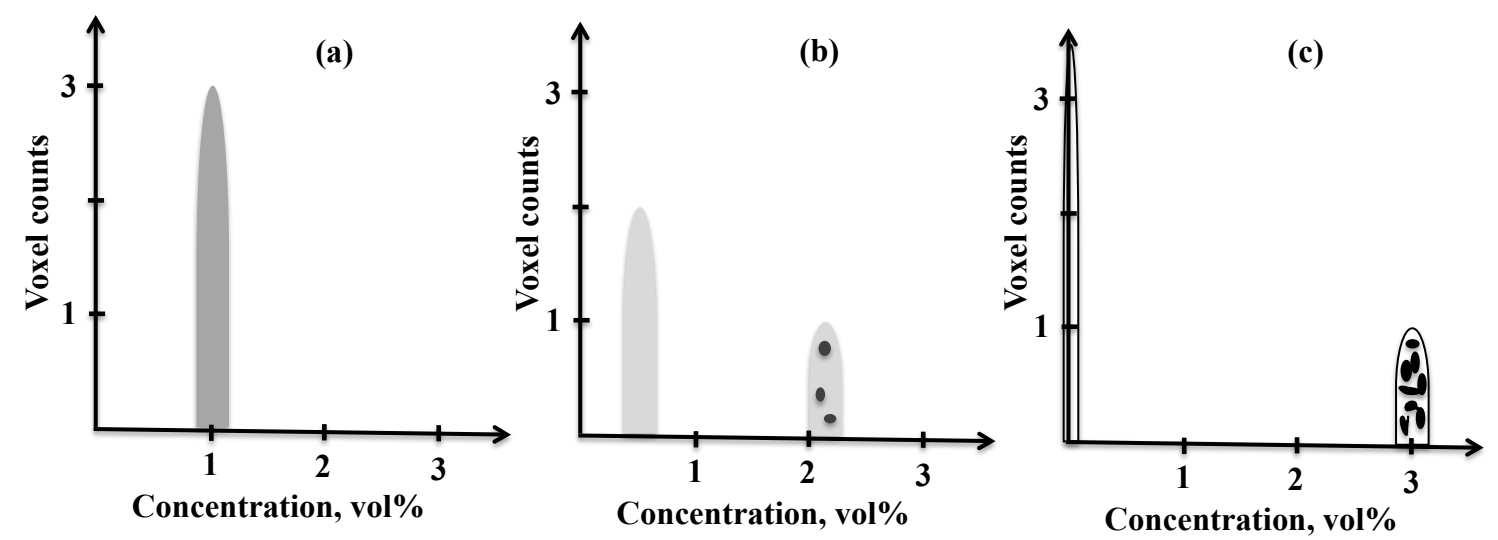

Fig. 2. Hypothetical histograms of three samples having the same 1 vol\% average formulation, but differing dispersions. Excellent dispersion (a) yields all voxels with the same component concentration. In the other limit (c) detectable lumps (black) and no dissolved component in the matrix (white background) yields the histogram on the right. An intermediate case (b), a bimodal histogram shows both a matrix (light grey) and some lumps (dark grey) with concentrations just above the detection threshold.

\section{Results and discussion}

In this study, three samples-A, B, C-are intentionally formulated to be deficient in flame retardant and synergist, while the fourth formulation-D-passes the UL 94 test. The samples are assessed with the UL 94 test and the burnt samples are studied with advanced X-ray imaging methods, namely, K-edge and single-shot grating interferometry tomography. 


\subsection{UL 94 and optical photos}

In the UL 94 test, samples A, B, and C drip and ignite cotton while sample D neither drips nor burns. The times and drip results give the V-ratings listed in Table 1. The best rating, V0 for sample D, is verified with duplicate samples. Sample D is rated as V-0 because it extinguishes within $2 \mathrm{~s}$ and there are no flaming polymer drips. Sample A drips to ignite the cotton, Fig. 1a, and extinguishes flame within $30 \mathrm{~s}$, hence a V-2 classification. Samples B and $\mathrm{C}$ ignite the cotton and burn longer than $30 \mathrm{~s}$, thus no classification. None of the samples are classified as V-1, meaning the burn stops within $30 \mathrm{~s}$ without drips.

Flaming drips are considered hazardous due to likely propagation of fire [44, 45]. Sample A lacks the bromine content to generate gaseous $\mathrm{HBr}$ and $\mathrm{SbBr}_{3}$, which act as free radical scavengers. Numerous studies have shown that when used alone, $\mathrm{Sb}_{2} \mathrm{O}_{3}$ is not an efficient flame retardant [32-34, 36, 46]. Similarly, magnesium or aluminum oxyhydroxides require extremely high concentrations for substantial reduction in polymer flammability [33, 47, 48].

Samples for single-shot X-ray checkerboard grating interferometry tomography, Fig. 3, were extracted from the burnt UL 94 polymer bars. The black region is called a char layer. Sample D' shows the most dense char layer while a glossy surface is observed on sample A'. The chemical information from the UL 94 test is limited. The X-ray experiments will reveal details of the flame retardancy performance.
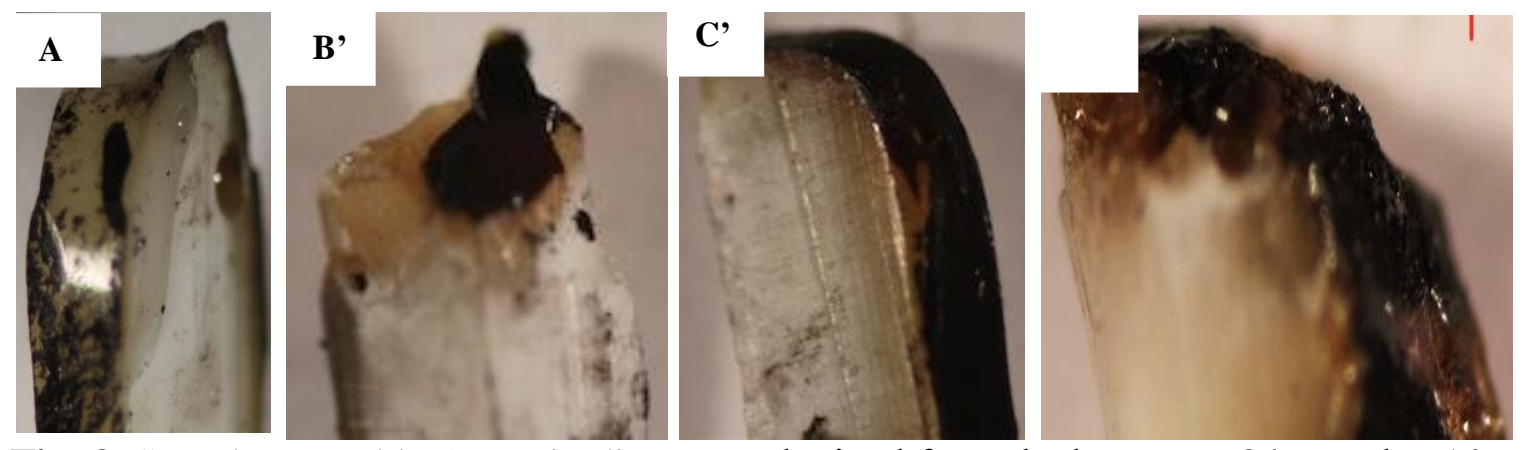

Fig. 3. Samples, roughly $1 \mathrm{~mm}$ in diameter, obtained from the burnt UL 94 samples A', B', C' and D' and used for single-shot grating interferometry. The nomenclature used herein is: letter code denotes sample formulation, prime indicates sample used for interferometry, and number is a sample used for K-edge tomography.

\section{2. $X$-ray single-shot $X$-ray checkerboard grating interferometry tomography}

The long-term goal for single-shot grating interferometry is dynamic imaging during a UL 94 test for both brominated and non-brominated flame retardants. Brominated flame retardants are X-ray compatible for absorption imaging due to the $\mathrm{Br} \mathrm{K}$-edge at $13.4 \mathrm{keV}$. Light element-boron, magnesium, aluminum, phosphorus-based flame retardants have low energy K-edges and are not easily detected with absorption X-ray imaging, thus the move to interferometry. Herein, GreenArmor ${ }^{\circledR}$ (BFR) is examined, a brominated polymeric flame retardant that exhibits exceptional blending with HIPS; it does not form the lumps characteristic with other flame retardants such as Saytex ${ }^{\circledR} 8010$ and Saytex ${ }^{\circledR}$ BT-93 [4, 5]. This exceptional blending makes GreenArmor ${ }^{\circledR}$ difficult to detect in a single-energy X-ray 
experiment. Multiple X-ray energy experiment will be reported next in section 3.3 X-ray Kedge absorption tomography. In this section, single-shot X-ray grating interferometry is evaluated as a method for detection of a protective char layer, gas bubble and microcrack formed by BFR and its synergist $\left(\mathrm{Sb}_{2} \mathrm{O}_{3}\right)$ in high impact polystyrene (HIPS).

X-ray interferometry yields three imaging modalities: absorption, dark-field (or small angle scattering) and differential phase contrast (DPC). The absorption image is identical to traditional X-ray imaging. The dark-field image can reveal features below detector pixel resolution [27]. The differential phase contrast shows interfaces by features such as gas bubbles in the sample. With sample rotation and acquisition of interferometry-based projections, three-dimensional (3D) volumes can be generated. In this work, the phase wrapping in the DPC images interferes with tomography reconstruction, so only DPC projections are presented.

Fig. 4 shows $\mathrm{D}^{\prime}$ and $\mathrm{C}^{\prime}$ in the three imaging modalities: orthoslices from absorption and dark-field tomography volumes, and two dimensional (2D) differential phase contrast projections. This analysis of post-burn samples is used to study BFR flame retardancy performance. Sample D exhibited high flame inhibition with $4 \mathrm{wt} \% \mathrm{Sb}_{2} \mathrm{O}_{3}$ and $\mathrm{C}$ showed low flame retardancy with a formulation of only $1 \mathrm{wt} \% \mathrm{Sb}_{2} \mathrm{O}_{3}$; both contained $13.3 \mathrm{wt} \%$ BFR.

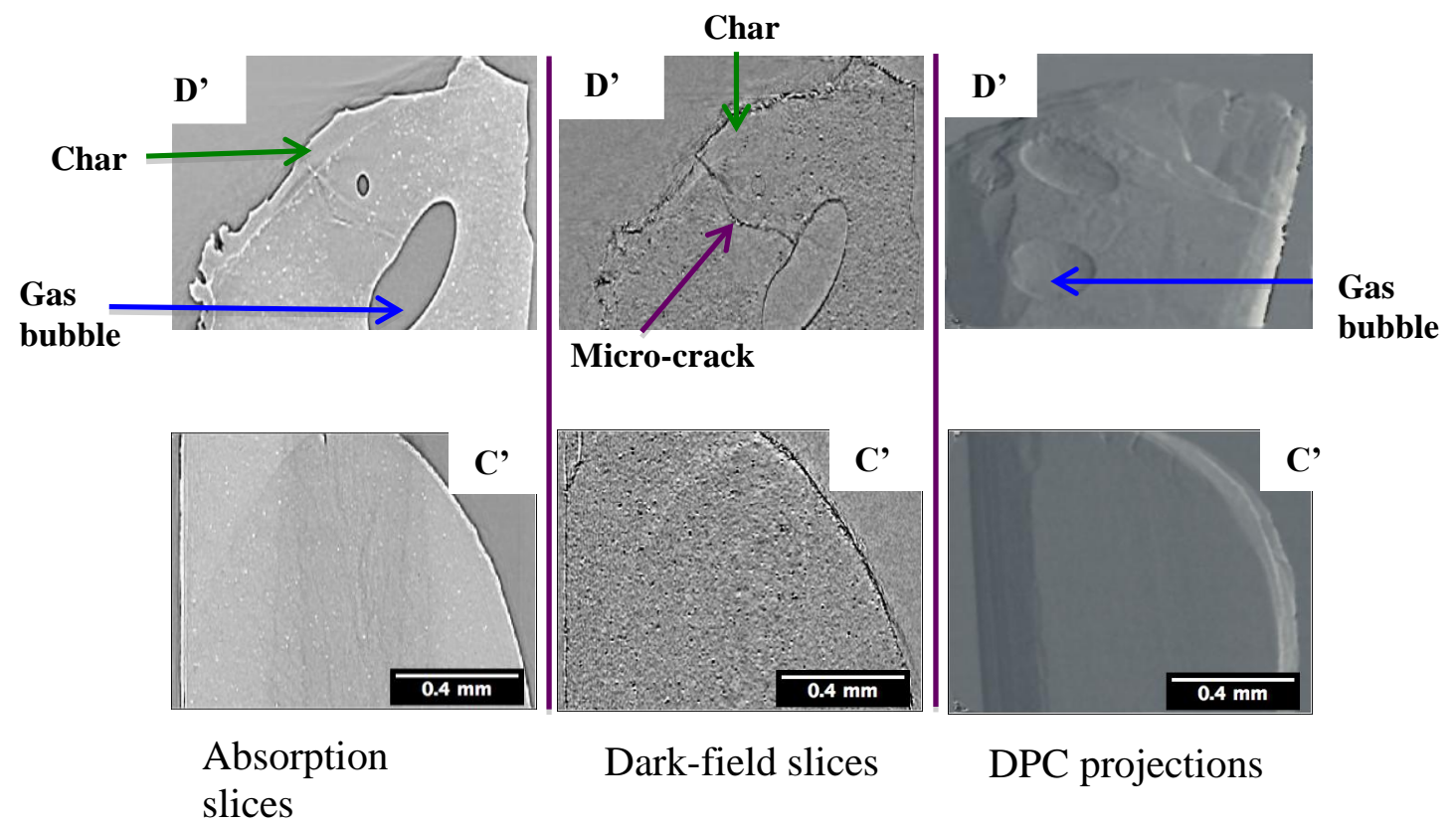

Fig. 4. The 2D absorption, dark-field orthoslices and projections of the differential phase contrast (DPC) images of $\mathrm{D}^{\prime}$ and $\mathrm{C}^{\prime}$ are presented to show $\mathrm{BFR} / \mathrm{Sb}_{2} \mathrm{O}_{3}$ blending in polymer systems and features of good flame retardancy. Samples D' and C' have equal scale bars.

Several features of interest are observed in Fig. 4. First, gas bubbles are found in D', and are definitively seen in the DPC projection. Such gas bubble formation is not observed in A', B' and C'. Second, char layer is easily recognized in D' as evident in orthoslices of the absorption volumes; the char layer is visible as a layer with uniform X-ray attenuation and small-angle scattering values. Third, extending into the sample, clear signs of heat are 
apparent with gas bubbles, cracks, and slight variations in X-ray attenuation. The cracks are nicely visible in the dark-field orthoslice. Gas bubbles are usually found in the heat affected region of the polymer, while there are none in the char layer. The gas bubbles are likely deflated in the char layer through the cracks leading to the surface and combustion. The synergist, $\mathrm{Sb}_{2} \mathrm{O}_{3}$ is less dissolved in comparison to the GreenArmor ${ }^{\circledR}$. Distinctive lumps are seen in the attenuation image. A speckle structure is seen in the dark-field image, which is attributed to incompletely dissolved lumps of $\mathrm{Sb}_{2} \mathrm{O}_{3}$. With heat and proximity to the char layer, the $\mathrm{Sb}_{2} \mathrm{O}_{3}$ lumps are observed to dissolve.

Sample C', which exhibits low flame retardancy based on UL 94 test, shows little internal structure due to a heat gradient; the sample image is a near constant value from the interior to the surface with no sign of a char layer, no evidence of dissolution of $\mathrm{Sb}_{2} \mathrm{O}_{3}$ lumps, no gas bubbles, and no cracks with possible gas flow to the surface. The remaining particles in $\mathrm{C}^{\prime}$ are $\mathrm{Sb}_{2} \mathrm{O}_{3}$, based on comparison to B' (BFR only) and $\mathrm{A}^{\prime}\left(\mathrm{Sb}_{2} \mathrm{O}_{3}\right.$ only) as shown in the Supporting Information Fig. S1. In the UL 94 test, sample $C$ has a long burn time relative to D. The absence of heat effects in the X-ray interferometry images of Sample C' is attributed to flow of molten polymer from the sample in the vertical UL 94 geometry.

For future X-ray interferometry experiments with C and D-type samples, i.e., successful and nearly successful flame retardants, a large field of view is needed to simultaneously visualize the flame, molten surface, and interior, non-heat affected polymer. This work shows that critical features of flame retardant performance can be seen in single-shot X-ray interferometry. The observation of these features for an exceptionally well-blended BFR suggests useful imaging results will also be obtained for other light-element flame retardants.

The X-ray absorption volume renderings (in maximum intensity) are shown in Supporting Information, Fig. S2, for particle distribution in the burnt samples. $\mathrm{Sb}_{2} \mathrm{O}_{3}$ lumps are relatively observed in A' absorption volume rendering in comparison to C' of $1 \mathrm{wt} \% \mathrm{Sb}_{2} \mathrm{O}_{3}$ and $\mathrm{D}^{\prime}$ of $4 \mathrm{wt} \% \mathrm{Sb}_{2} \mathrm{O}_{3}$.

\subsection{X-ray K-edge absorption tomography}

$\mathrm{X}$-ray K-edge absorption tomography provides a concentration distribution within the UL 94 burnt samples. Multiple X-ray data acquisitions across $\mathrm{Br}$ and $\mathrm{Sb} \mathrm{K}$-edges, combined with sample density and linear X-ray attenuation data for the components, is used to map the $\mathrm{X}$-ray attenuation into three-dimensional (3D) concentration maps. The units are vol\% BFR and $\mathrm{Sb}_{2} \mathrm{O}_{3}$ but it is recognized that both species may be partially decomposed due to heat from the UL 94 test. Below, raw data is presented, tomography at 12, 25 and $32 \mathrm{keV}$, and the $3 \mathrm{D}$ concentration volumes. The average vol\% BFR and $\mathrm{Sb}_{2} \mathrm{O}_{3}$ in the $3 \mathrm{D}$ volumes are less than in the formulation due to partial combustion of the samples. The line probes across char layers show a concentration gradient due to consumption of BFR.

\subsubsection{Tomography data from 12 to $32 \mathrm{keV}$}

At all X-ray energies used, both $\mathrm{Br}$ and $\mathrm{Sb}$ contribute to X-ray absorption. Orthoslices from tomography at $12 \mathrm{keV}$ are shown in Fig. 5. First, sample A1, formulated with only $\mathrm{Sb}_{2} \mathrm{O}_{3}$, shows some undissolved $\mathrm{Sb}_{2} \mathrm{O}_{3}$ particles. Later, the $3 \mathrm{D}$ concentration volume will be used to 
assess the fraction of $\mathrm{Sb}_{2} \mathrm{O}_{3}$ that exists as detectable particles using the histogram analysis described in section 2.5. Sample B1, formulated with only BFR, shows no lumps; this indicates that BFR is well dispersed in the polymer and that lumps observed in other images are attributed to undissolved $\mathrm{Sb}_{2} \mathrm{O}_{3}$ particles. Sample D1, containing optimal concentrations of BFR and $\mathrm{Sb}_{2} \mathrm{O}_{3}$ for flame retardancy, shows a successful char layer. Conversely, $\mathrm{C} 1$, containing BFR and a minor amount of $\mathrm{Sb}_{2} \mathrm{O}_{3}$, does not show a successful char layer.

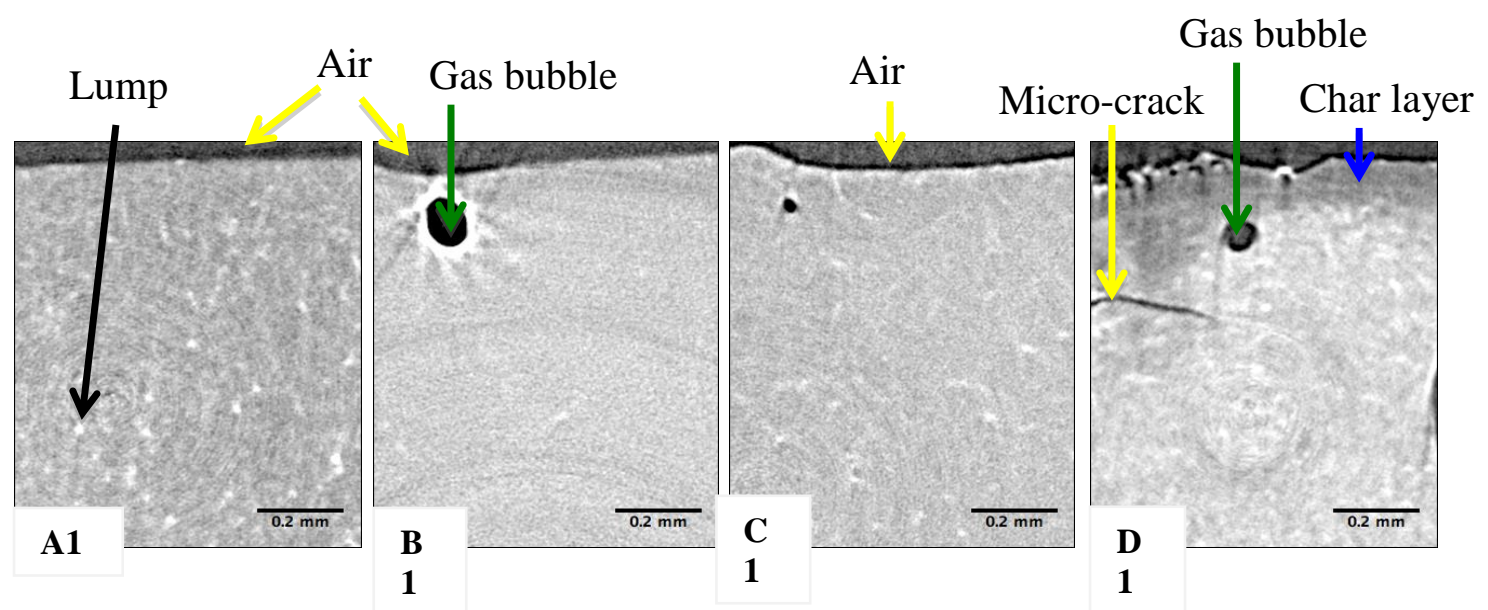

Fig. 5. Tomography at $12 \mathrm{keV} \mathrm{X}$-ray for samples containing only $\mathrm{Sb}_{2} \mathrm{O}_{3}$ (A1), only BFR (B1), BFR and minor $\mathrm{Sb}_{2} \mathrm{O}_{3}$ (C1), and optimal concentrations of BFR and $\mathrm{Sb}_{2} \mathrm{O}_{3}$ (D1). Lumps in $\mathrm{A} 1, \mathrm{C} 1$, and $\mathrm{D} 1$ are attributed to undissolved $\mathrm{Sb}_{2} \mathrm{O}_{3}$ particles. The BFR is very well blended in high impact polystyrene (HIPS) as shown in B1.

When the samples are imaged at an X-ray energy above the Sb K-edge, and then visualized in $2 \mathrm{D}$ showing the maximum voxel absorption of a $3 \mathrm{D}$ volume, the $\mathrm{Sb}_{2} \mathrm{O}_{3}$ lumps are prominent, as shown in Fig. 6. The 3D volumes have 512 slices and maximum voxel absorption selects the largest absorption value along the slice direction for display in the orthogonal plane. As the $\mathrm{Sb}_{2} \mathrm{O}_{3}$ concentration increases, particles of $\mathrm{Sb}_{2} \mathrm{O}_{3}$ become visible in the order $\mathrm{C} 1<\mathrm{D} 1 \approx \mathrm{A} 1$. The large difference between images of 1 and $4 \mathrm{wt} \% \mathrm{Sb}_{2} \mathrm{O}_{3}$ suggest a lump threshold, as introduced in section 2.5. The maximum voxel absorption visualization mode is applied to volumes containing 512 slices. This visualization mode highlights lumps but does not show gas bubbles. Sample B1, containing only BFR, shows excellent dispersion. The curved lines are due to scintillator defects. The stacked slices of average intensity at $32 \mathrm{keV}$ are included in the Supporting Information Fig. S3 with high absorption value in D1 and D2. 

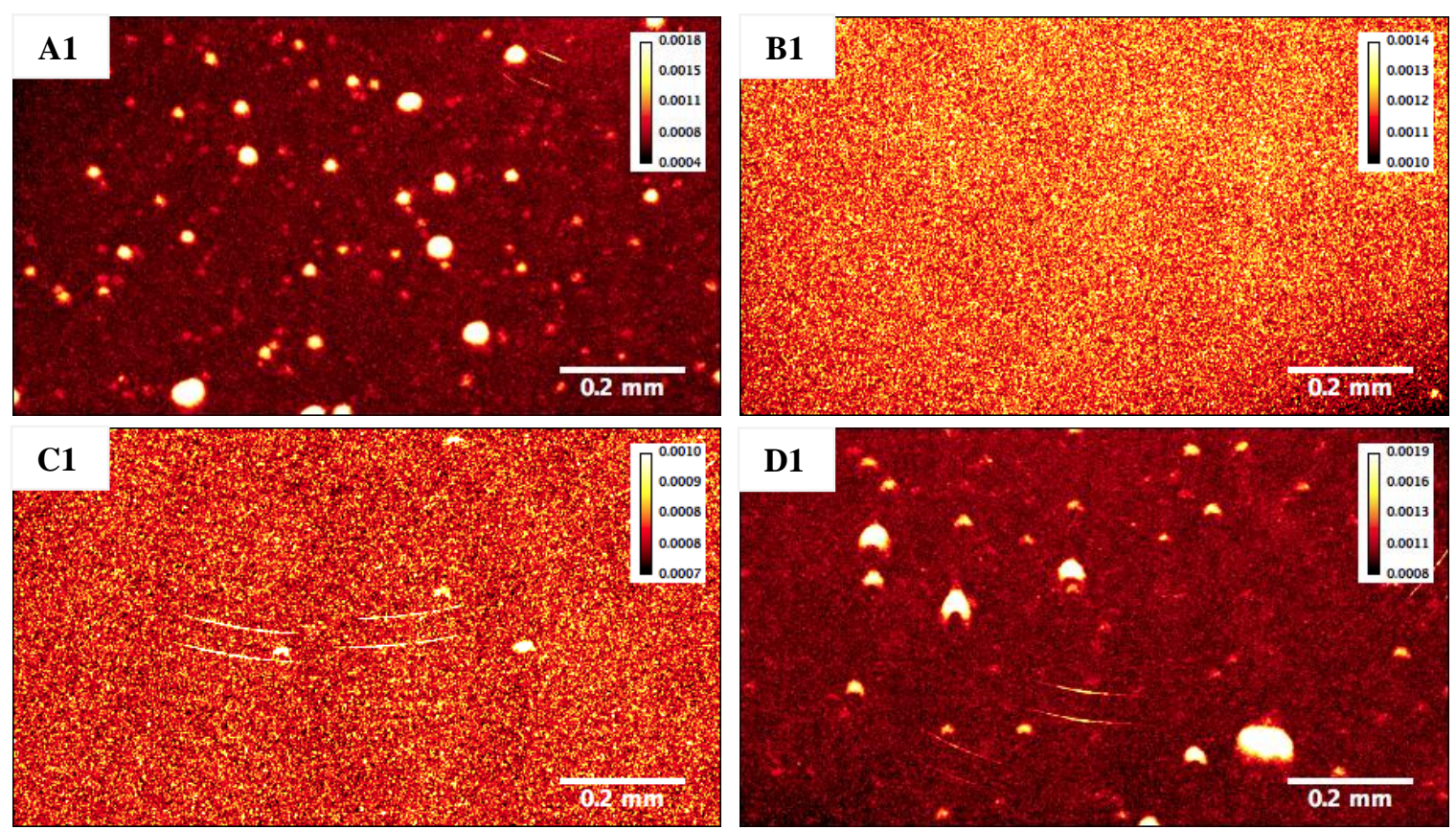

Fig. 6. At $32 \mathrm{keV}$ (A1, C1 and D1) and $25 \mathrm{keV}(\mathrm{B} 1)$, only the samples with $4 \mathrm{wt} \% \mathrm{Sb}_{2} \mathrm{O}_{3}$, samples A1, D1, show many lumps in this 3D to 2D visualization mode.

\subsubsection{Concentration volumes of $\mathrm{BFR}$ and $\mathrm{Sb}_{2} \mathrm{O}_{3}$}

The tomography datasets from $12 \mathrm{keV}$ to $32 \mathrm{keV}$, up to six energies for a sample, were fitted by least-squares to a linear model for vol\% concentrations of HIPS, BFR, and $\mathrm{Sb}_{2} \mathrm{O}_{3}$. The mean concentrations and other parameters are given in Table 2 and 3 for BFR and $\mathrm{Sb}_{2} \mathrm{O}_{3}$, respectively. For these partially burnt samples, the mean concentrations are less than the formulation, as expected. In Table 2, the difference between formulation and calculated average vol\% of BFR $(\mathrm{B} 1<\mathrm{C} 1<\mathrm{D} 1<\mathrm{D} 2)$ is consistent with the formation of char layers and gas bubbles. The high standard deviation in BFR vol\% is due to char layer and gas bubbles of low vol\% (and zero vol\% when masked) of the partially burnt sample. For the purpose of assessing the absolute accuracy of the K-edge concentration analysis, the results for an unburnt sample, D3, are extracted from a previous study and listed in Tables 2 and 3 [5]. D3 is composed of $12 \mathrm{wt} \%$ BFR (Saytex $\left.{ }^{\circledR} 8010\right), 4 \mathrm{wt} \% \mathrm{Sb}_{2} \mathrm{O}_{3}$ and $84 \mathrm{wt} \%$ HIPS.

For the $\mathrm{Sb}_{2} \mathrm{O}_{3}$ particles (synergist) in Table 3, the difference between formulation and $\mathrm{K}$ edge measurement is small. There is concentration enhancement effect due to antimonycontaining species deposited as solids in the char layer. Both D1 and D2 show high standard deviations for $\mathrm{Sb}_{2} \mathrm{O}_{3}$ concentration. Samples $\mathrm{B} 1$ and $\mathrm{C} 1$ have subtle char layers and smaller standard deviations. The lumps clearly visible in Fig. 6 are not pure $\mathrm{Sb}_{2} \mathrm{O}_{3}$; the last column of Table 3 gives the maximum vol\% concentration within the 3D volume, which is always much smaller than 100 vol\%. 
Table 2 Calculated vol\% Concentration of BFR for D3 [5], B1, C1, D1 and D2.

\begin{tabular}{|c|c|c|c|}
\hline Samples & $\begin{array}{c}\text { Original formulation } \\
\text { BFR, vol\% }\end{array}$ & $\begin{array}{c}\text { Calculated } \\
\text { average BFR, } \\
\text { vol\% }\end{array}$ & $\begin{array}{c}\text { Std. } \\
\text { deviation, } \\
\text { vol\% }\end{array}$ \\
\hline B1 & 6.48 & 4.97 & 0.51 \\
\hline C1 & 6.54 & 4.65 & 0.49 \\
\hline D1 & 6.72 & 4.80 & 0.86 \\
\hline D2 & 6.72 & 4.58 & 0.62 \\
\hline D3 & 4.34 & 3.76 & 0.66 \\
\hline
\end{tabular}

Table 3 Calculated vol\% Concentration of $\mathrm{Sb}_{2} \mathrm{O}_{3}$ for A1, D3 [5], C1, D1 and D2.

\begin{tabular}{|c|c|c|c|c|}
\hline Samples & $\begin{array}{c}\text { Original } \\
\text { formulation } \mathrm{Sb}_{2} \mathrm{O}_{3}, \\
\text { vol\% }\end{array}$ & $\begin{array}{c}\text { Calculated average } \\
\mathrm{Sb}_{2} \mathrm{O}_{3}, \text { vol\% }\end{array}$ & $\begin{array}{c}\text { Std. } \\
\text { deviation, } \\
\text { vol\% }\end{array}$ & $\begin{array}{c}\text { Maximum, } \\
\text { vol\% }\end{array}$ \\
\hline $\mathrm{A} 1$ & 0.76 & 0.53 & 0.19 & 12.27 \\
\hline $\mathrm{C} 1$ & 0.20 & 0.17 & 0.16 & 1.88 \\
\hline D1 & 0.82 & 0.59 & 0.23 & 5.22 \\
\hline D2 & 0.82 & 0.55 & 0.25 & 17.38 \\
\hline D3 & 0.83 & 0.70 & 0.39 & 14.04 \\
\hline
\end{tabular}

Orthoslices from the K-edge chemical concentration measurements show better dispersion of BFR relative to the $\mathrm{Sb}_{2} \mathrm{O}_{3}$ synergist in the polymer blends, Fig. 7. The dark holes in the BFR vol\% slices in $\mathrm{C} 1, \mathrm{D} 1$ and $\mathrm{D} 2$ are due to an $\mathrm{Sb}_{2} \mathrm{O}_{3}$ lump, as shown by bright spot in the corresponding $\mathrm{Sb}_{2} \mathrm{O}_{3}$ vol\% slice. As observed in Fig. 8b, $\mathrm{Sb}_{2} \mathrm{O}_{3}$ lumps are observed at a concentration of $0.8 \mathrm{vol} \%$ (A1), amounting to $11.6 \%$ of all $\mathrm{Sb}_{2} \mathrm{O}_{3}$. The majority of $\mathrm{Sb}_{2} \mathrm{O}_{3}$ is dispersed in the polymer blend. It is noted that no voxels containing only $\mathrm{Sb}_{2} \mathrm{O}_{3}$ were found; the maximum $\mathrm{Sb}_{2} \mathrm{O}_{3}$ concentration found is $17.38 \mathrm{vol} \%$ (Table 3). 


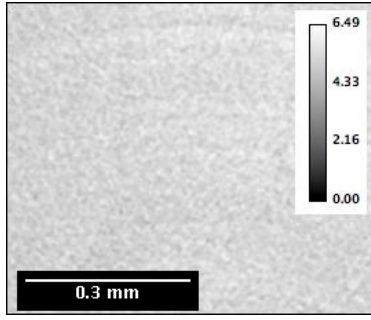

$\mathrm{A} 1: \mathrm{Sb}_{2} \mathrm{O}_{3} \mathrm{vol} \%$

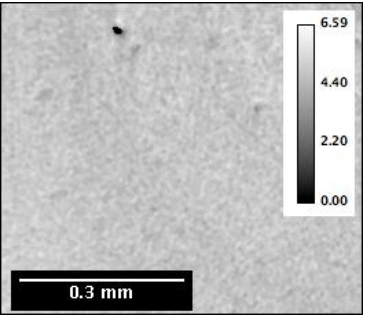

$\mathrm{C} 1: \mathrm{Sb}_{2} \mathrm{O}_{3} \mathrm{vol}_{\%}$

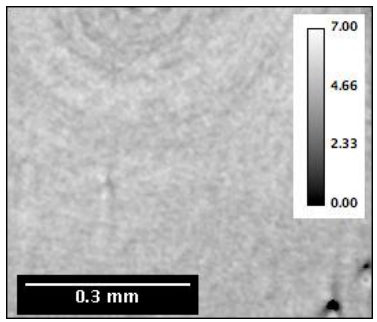

$\mathrm{D} 1: \mathrm{Sb}_{2} \mathrm{O}_{3} \mathrm{vol} \%$

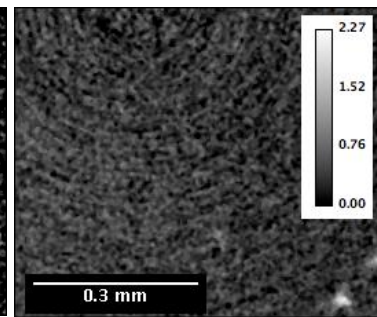

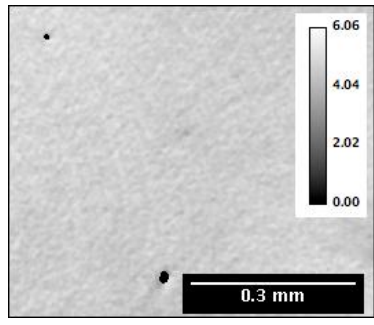

D2: $\mathrm{Sb}_{2} \mathrm{O}_{3}$ vol\%

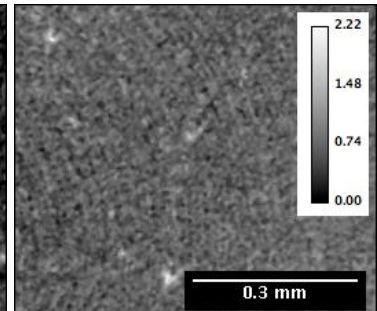

Fig. 7. Selected slices of the burnt samples after K-edge analysis show that BFR (top row) homogeneity is better than $\mathrm{Sb}_{2} \mathrm{O}_{3}$ (bottom row) homogeneity in polymer blends. The colorbars are in units of vol\%.

Histograms of the K-edge tomography data are shown in Fig. 8 where the analysis starts with A1. Line probe across representative $\mathrm{Sb}_{2} \mathrm{O}_{3}$ particles in A1 showed a detectability of $0.8 \mathrm{vol} \%$ for visual observation of particles in the orthoslices (see Supporting Information Fig. S4). Therefore, the $\mathrm{Sb}_{2} \mathrm{O}_{3}$ histogram in Fig. $8 \mathrm{~b}$ for A1 uses 0.8 vol\% as a threshold value for estimating the fraction of $\mathrm{Sb}_{2} \mathrm{O}_{3}$ existing in particles. With this threshold, $11.6 \%$ of all $\mathrm{Sb}_{2} \mathrm{O}_{3}$ exists in detectable lumps; the bulk of $\mathrm{Sb}_{2} \mathrm{O}_{3}$ is dispersed in the polymer matrix. Samples D1 and D2 also shows lumps in the $12 \mathrm{keV}$ orthoslice and $32 \mathrm{keV}$ maximum voxel absorption images; the histogram shows a similar fraction of $\mathrm{Sb}_{2} \mathrm{O}_{3}$ concentration above the 0.8 vol\% threshold. Conversely, very few $\mathrm{Sb}_{2} \mathrm{O}_{3}$ lumps are observed in $\mathrm{C} 1$ formulated with only 1 vol\% $\mathrm{Sb}_{2} \mathrm{O}_{3}$, and the histogram shows scarcely any voxels with concentrations above 0.8 vol\%. No lumps are observed for BFR. The histograms for D1 and D2 are different at the low concentration, reflecting the larger char volume in D2. 

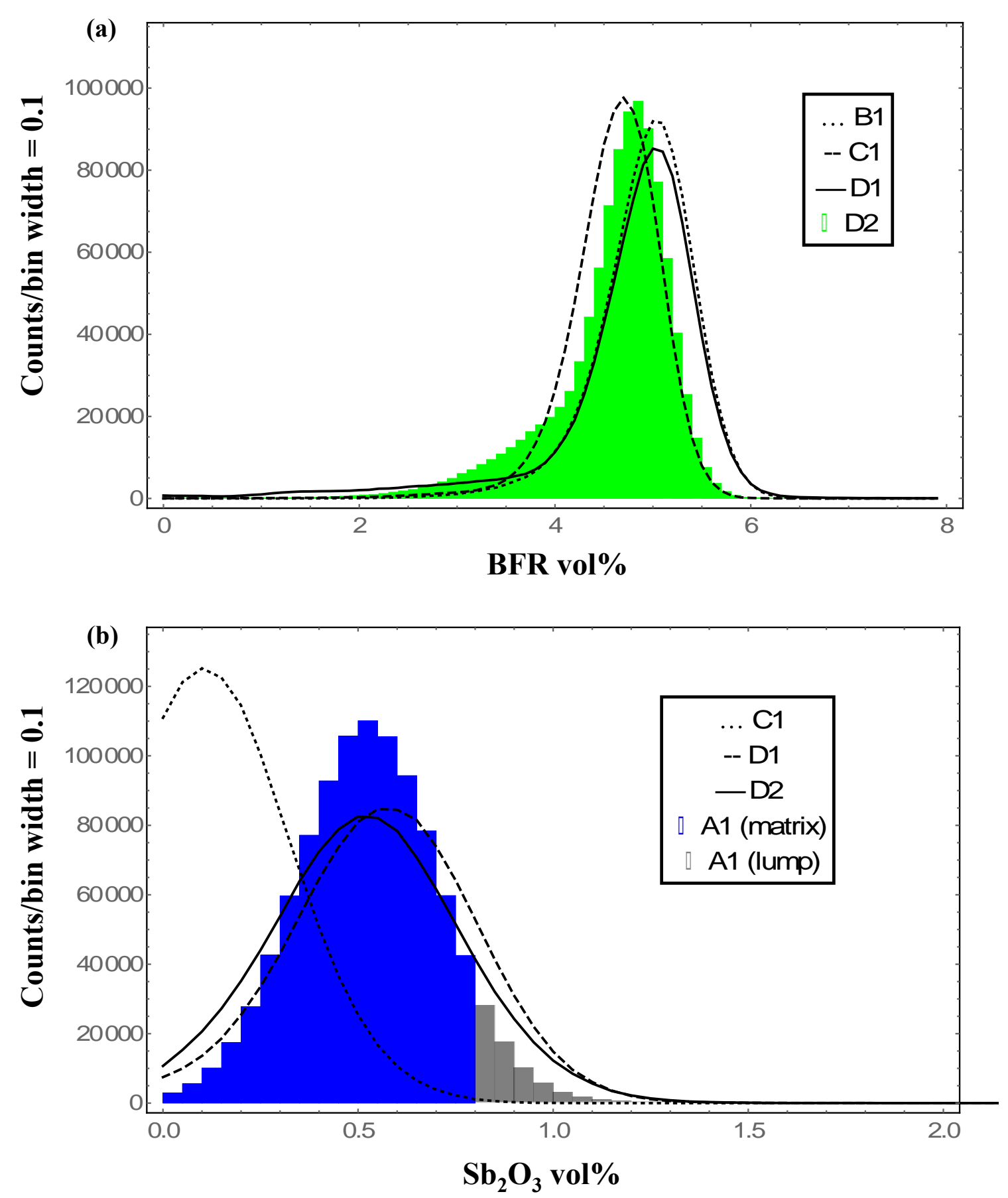

Fig. 8. The K-edge tomography data is presented as histograms to quantify the distributions of BFR and $\mathrm{Sb}_{2} \mathrm{O}_{3}$ observed in Fig. 7. The $\mathrm{Sb}_{2} \mathrm{O}_{3}$, in $\mathrm{A} 1$ shows lumps at a threshold $\geq 0.8$ $\mathrm{vol} \%$, and is shown in gray. The area of the gray region amounts to only $11.6 \%$ of all $\mathrm{Sb}_{2} \mathrm{O}_{3}$ in A1.

\subsubsection{Line probes in volumes of $\mathrm{BFR}$ and $\mathrm{Sb}_{2} \mathrm{O}_{3}$, vol\%}

For surfaces on the burnt samples that can be identified as a char layer, either through X-ray or optical images, line probes, Fig. 9, are used to assess the BFR and $\mathrm{Sb}_{2} \mathrm{O}_{3}$ concentration 
gradients through the char layer and into the pristine sample. As much as possible, the line probes are perpendicular to the surface through visual placement of start and stop points. The start point is at the sample surface, which is easy to locate in the X-ray volumes of all samples except D1 BFR vol\%, as shown in Fig. 10 due to low char layer concentration.

For BFR vol\%, samples D1 and D2 exhibit lower concentration in the char layer, especially sample D2, from the surface to $0.22 \mathrm{~mm}$. This low vol\% is due both to consumption of BFR and the preservation of some of the polymer sample as a char layer. Samples D1 and D2 are cut from the same burnt polymeric bar at nearly the same height above the methane burner region. Variations between D1 and D2 could be due to inconsistent blending, sample damage during cutting from the bar (the char layer is delicate), and/or a strong temperature gradient along the burn bar. In comparison to the D samples, B1 and C1 show hardly any char layer. And all samples show in the interior a nearly pristine sample-the polymer blend is less affected by heat-with a high BFR and $\mathrm{Sb}_{2} \mathrm{O}_{3}$ vol\%. In the $\mathrm{Sb}_{2} \mathrm{O}_{3}$ line probe plot, the $\mathrm{Sb}_{2} \mathrm{O}_{3}$ lumps yield a high standard deviation in all line probes, even with averaging to a radius of 10 voxels. Sample $\mathrm{C} 1$ was formulated with low $\mathrm{Sb}_{2} \mathrm{O}_{3}$ concentration, and this is verified with its line probe to the interior. The pristine sample regions are identifiable based on previous experience with a $12 \mathrm{wt} \%$ Saytex $^{\circledR} 8010$ as $\mathrm{BFR}+4 \mathrm{wt} \% \mathrm{Sb}_{2} \mathrm{O}_{3}+84 \mathrm{wt} \%$ HIPS) [5]. In that work, it was observed that gas bubbles and lump dissolution are early features of heat affects.
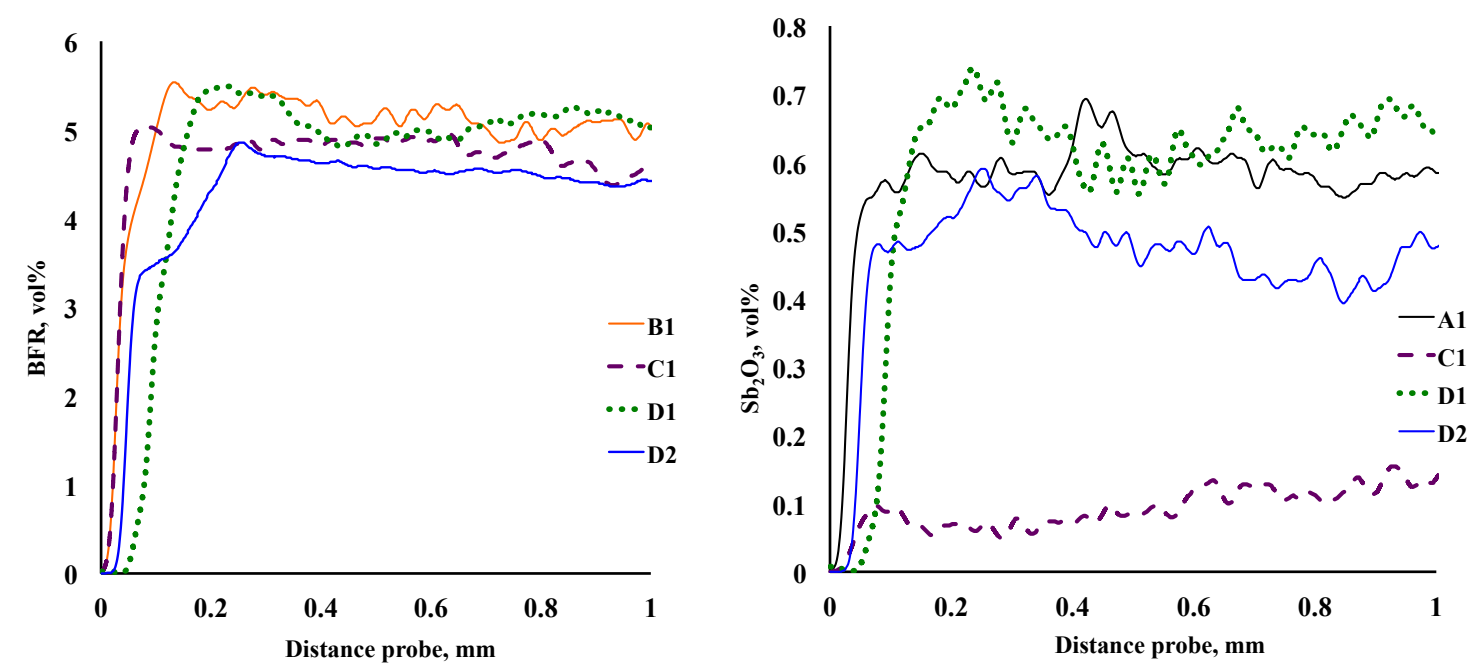

Fig. 9. The BFR and $\mathrm{Sb}_{2} \mathrm{O}_{3}$ vol\% line probes of the UL 94 data sets from sample surface, passing through the char layer, and going into the pristine sample. The line probe averages concentration to a radius of 10 voxels $(25 \mu \mathrm{m})$. The roughly $0.22 \mathrm{~mm}$ thick char layer is most pronounced in BFR for D2 and less so for D1. For $\mathrm{Sb}_{2} \mathrm{O}_{3}$, the line probes are affected by lumps.

\subsubsection{Features observed in the $\mathrm{BFR}$ and $\mathrm{Sb}_{2} \mathrm{O}_{3}$ volumes}

With increased $\mathrm{Sb}_{2} \mathrm{O}_{3} \mathrm{wt} \%$ in D1 formulation, unlike $\mathrm{C} 1$ and $\mathrm{B} 1$, more features are observed that are correlated with its better flame retardancy. In D1, more gas bubbles are observed. In $\mathrm{B} 1$ and $\mathrm{C}$, only one gas bubble is observed throughout the volume analyzed, and no gas bubbles are observed at all in A1. In addition to the gas bubbles, D1 shows a highly visible 
char layer and a crack, as shown in Fig. 5. There seems to be a connection between cracks and gas bubbles that lead to gas bubble deflation in the polymer char layer (see also Fig. 4). At this point, it is inferred that the formation of the char layer and gas bubbles are necessary factors for a successful flame retardant with a high UL 94 test rating. All attributes of a successful flame retardant formulation are exhibited by D1 and D2.

Lastly, in Fig. 10, the volume renderings of BFR and $\mathrm{Sb}_{2} \mathrm{O}_{3}$ vol\% concentration of A1, B1, D1 and D2 are presented to supplement the orthoslices shown in Fig. 7. Samples B1, D1 and D2 show excellent BFR homogeneity; the $\mathrm{Sb}_{2} \mathrm{O}_{3}$ component is moderately well dispersed. Figs. 10d, 10e and 10f allow comparison of $\mathrm{Sb}_{2} \mathrm{O}_{3}$ particles in $\mathrm{A} 1, \mathrm{D} 1$ and D2; all have 4 wt $\% \mathrm{Sb}_{2} \mathrm{O}_{3}$. For $\mathrm{D} 1$ and $\mathrm{D} 2, \mathrm{Sb}_{2} \mathrm{O}_{3}$ lumps are few in number, i.e., well dispersed, even though the histogram, Fig. 8b, shows many voxels with concentrations above the threshold for visible lump formation, as seen for the $\mathrm{Sb}_{2} \mathrm{O}_{3}$ distribution in $\mathrm{A} 1$. In other words, the volume renderings suggest $\mathrm{BFR}$ aids $\mathrm{Sb}_{2} \mathrm{O}_{3}$ dissolution while the histogram data shows the opposite and is the preferred interpretation. Line probes across $\mathrm{Sb}_{2} \mathrm{O}_{3}$ lumps in D1 and D2 are consistent with a lump threshold of $0.8 \mathrm{vol} \%$. 
Sample B1: BFR vol\%

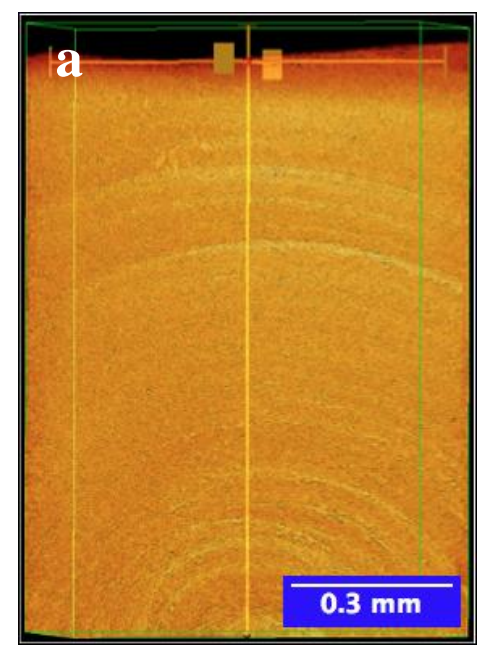

Sample A1: $\mathrm{Sb}_{2} \mathrm{O}_{3}$ vol\%

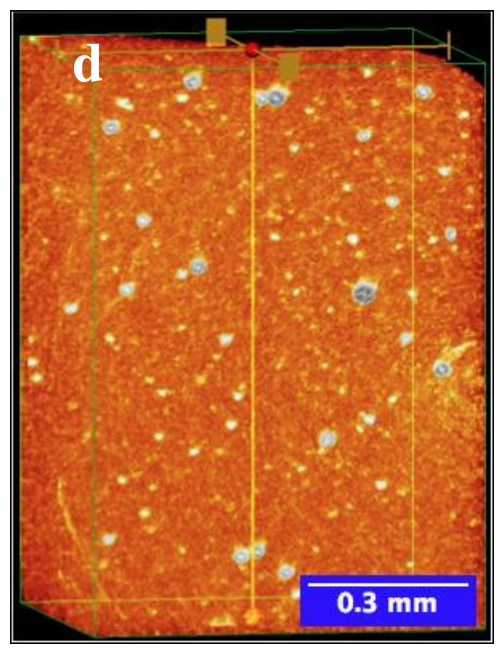

Sample D1: BFR vol\%

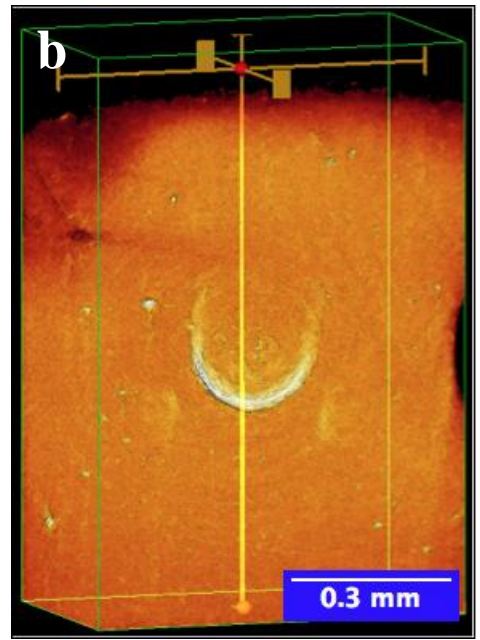

Sample D1: $\mathrm{Sb}_{2} \mathrm{O}_{3}$ vol\%

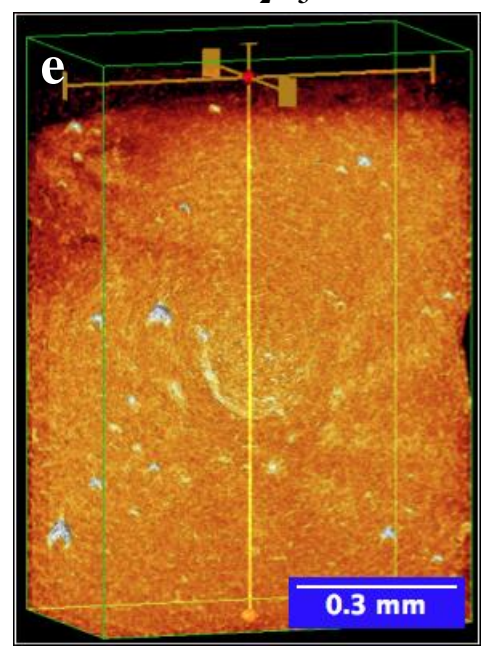

Sample D2: BFR vol\%

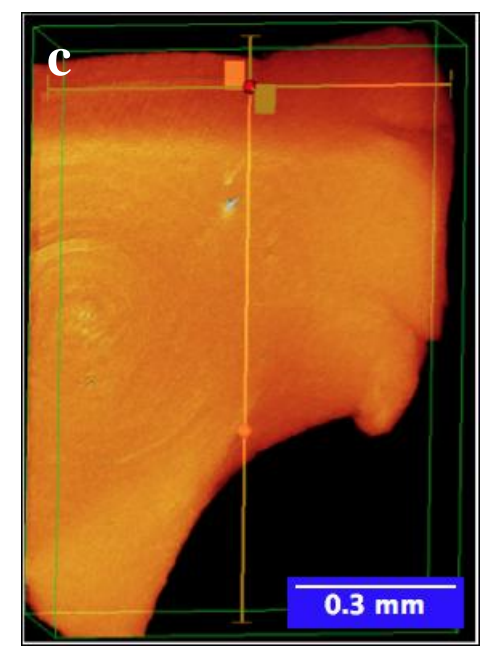

Sample D2: $\mathrm{Sb}_{2} \mathrm{O}_{3}$ vol\%

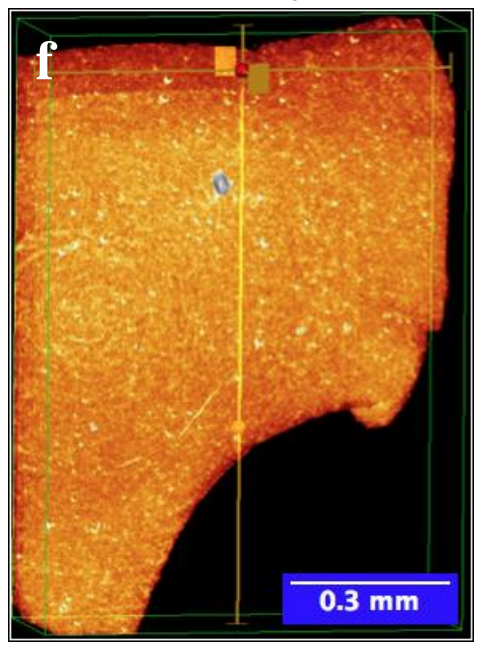

Fig. 10. The volume renderings show the BFR vol\% and $\mathrm{Sb}_{2} \mathrm{O}_{3}$ vol\% of burnt $\mathrm{A} 1, \mathrm{~B} 1, \mathrm{D} 1$, and D2. For B1, D1 and D2, the images show a much better dispersion of BFR than $\mathrm{Sb}_{2} \mathrm{O}_{3}$. A char layer is clearly visible in all D images at the top of the sample, but no char layer is observed in the volume rendering for A1 even though the burn surface is known to be at the top of the sample. The vectors for the line probes, Fig. 9, are shown by the orange lines. The bright circular spot near the center of D1 is a ring artifact.

\section{Conclusions}

X-ray imaging methods are still maturing, but are now able to offer new insights into flame retardant polymers. The K-edge tomography for a Br-Sb system is slow, typically using five to seven tomography volumes. The method of single-shot X-ray interferometry/tomography is promising, aside from the problem of a small field of view with these newly developed Xray optics.

The sample series consisted of a correctly formulated $\mathrm{BFR} / \mathrm{Sb}_{2} \mathrm{O}_{3}$ sample $\mathrm{D}$ and others, including $\mathrm{C}$ with insufficient $\mathrm{Sb}_{2} \mathrm{O}_{3}$ concentration. The comparison between burnt samples of $\mathrm{C}$ and $\mathrm{D}$ shows failure to form a protective char layer in $\mathrm{C}$, but a distinctive char layer in 
D along with gas bubbles, $\mathrm{Sb}_{2} \mathrm{O}_{3}$ lump dissolution, and cracks. The BFR (GreenArmor ${ }^{\circledR}$ ) is homogeneously blended in HIPS. From an imaging perspective, excellent blending reduces the information content of single X-ray energy attenuation images. For example, BFR lump dissolution at the char layer was helpful in a study of Saytex 8010 [5], a BFR that forms lumps in HIPS. While K-edge imaging can recover concentration information, the method is slow and computationally demanding. Both methods of X-ray imaging, K-edge absorption tomography and single-shot grating interferometry, revealed char layer features for these homogenous samples. This bodes well for monitoring light-element flame retardants, which are not likely to show up well in attenuation imaging. The single-shot X-ray interferometry should be developed into a real-time imaging method for enhanced UL 94 testing. The problem of phase wrapping, occurring due to the high absorbing components of bromine and antimony in BFR- $\mathrm{Sb}_{2} \mathrm{O}_{3}$ polymer blends, in differential phase contrast images is expected to be minimal when X-ray interferometry imaging is applied to study nonhalogenated flame retardant additives.

The new single-shot X-ray interferometer with a unique checkerboard phase grating [28] has some limitations. The checkerboard phase grating and detector combination have a small field of view of about $1 \mathrm{~mm}$. Cutting the sample to fit into this field of view risks damage to the delicate char layer. The operational X-ray energy with current X-ray optics is only 22 $\mathrm{keV}$. As better optics are developed, operation at higher X-ray energy will reduce the problem of phase wrapping at the air-sample interface.

\section{Acknowledgements}

Use of the Advanced Photon Source and Center for Nanoscale Materials, Office of Science User Facilities operated for the U.S. Department of Energy (DOE), Office of Science, by Argonne National Laboratory, was supported by the U.S. DOE under Contract No. DEAC02-06CH11357. The support of National Science Foundation (NSF) CHE-0910937, 1610655 and W.M. Keck Foundation is gratefully acknowledged. This material is based upon work supported by the National Science Foundation under the NSF EPSCoR Cooperative Agreement No. EPS-1003897 with additional support from the Louisiana Board of Regents. Mutairu B. Olatinwo would like to thank the A.G. Leventis Foundation and Alpha Kappa Alpha Educational Advancement Foundation for their additional research support.

\section{References}

[1] Albemarle licenses Dow's polymeric flame retardant technology, reports 1Q growth, Additives for Polymers 2012(6) (2012) 5.

[2] H.A. Barnett, K. Ham, J.T. Scorsone, L.G. Butler, Synchrotron X-ray Tomography for 3D Chemical Distribution Measurement of a Flame Retardant and Synergist in a FiberglassReinforced Polymer Blend, J. Phys. Chem. B 114(1) (2010) 2-9.

[3] H.A. Barnett, K. Ham, L.G. Butler, Synchrotron X-ray tomography for 3D chemical diffusion measurement of a flame retardant in polystyrene, Nucl. Instr. Meth. Phys. Res. A 582(1) (2007) 202-204. 
[4] K. Ham, H. Jin, R. Al-Raoush, X.G. Xie, C.S. Willson, G.R. Byerly, L.S. Simeral, M.L. Rivers, R.L. Kurtz, L.G. Butler, Three-dimensional chemical analysis with synchrotron tomography at multiple $\mathrm{x}$-ray energies: Brominated aromatic flame retardant and antimony oxide in polystyrene, Chem. Mater. 16(21) (2004) 4032-4042.

[5] M.B. Olatinwo, K. Ham, J. McCarney, S. Marathe, J. Ge, G. Knapp, L.G. Butler, Analysis of Flame Retardancy in Polymer Blends by Synchrotron X-ray K-edge Tomography and Interferometric Phase Contrast Movies, J. Phys. Chem. B (2016).

[6] T. Weitkamp, A. Diaz, C. David, F. Pfeiffer, M. Stampanoni, P. Cloetens, E. Ziegler, Xray phase imaging with a grating interferometer, Opt. Express 13(16) (2005) 6296-6304.

[7] F. Pfeiffer, Milestones and basic principles of grating-based x-ray and neutron phasecontrast imaging, AIP Conf. Proc. 1466(1) (2012) 2-11.

[8] F. Pfeiffer, M. Bech, O. Bunk, P. Kraft, E.F. Eikenberry, C. Bronnimann, C. Grunzweig, C. David, Hard-X-ray dark-field imaging using a grating interferometer, Nat. Mater. 7(2) (2008) 134-137.

[9] A. Sarapata, M. Ruiz-Yaniz, I. Zanette, A. Rack, F. Pfeiffer, J. Herzen, Multi-contrast 3D X-ray imaging of porous and composite materials, Appl. Phys. Lett. 106(15) (2015).

[10] P.P. Zhu, K. Zhang, Z.L. Wang, Y.J. Liu, X.S. Liu, Z.Y. Wu, S.A. McDonald, F. Marone, M. Stampanoni, Low-dose, simple, and fast grating-based X-ray phase-contrast imaging, Proc. Natl. Acad. Sci. U. S. A. 107(31) (2010) 13576-13581.

[11] H. Miao, A.A. Gomella, K.J. Harmon, E.E. Bennett, N. Chedid, S. Znati, A. Panna, B.A. Foster, P. Bhandarkar, H. Wen, Enhancing Tabletop X-Ray Phase Contrast Imaging with Nano-Fabrication, Sci. Rep. 5 (2015) 13581.

[12] A. Momose, W. Yashiro, K. Kido, J. Kiyohara, C. Makifuchi, T. Ito, S. Nagatsuka, C. Honda, D. Noda, T. Hattori, T. Endo, M. Nagashima, J. Tanaka, X-ray phase imaging: from synchrotron to hospital, Phil. Trans. R. Soc. A 372(2010) (2014).

[13] A. Momose, S. Kawamoto, I. Koyama, Y. Hamaishi, K. Takai, Y. Suzuki, Demonstration of X-Ray Talbot interferometry, Jpn. J. of Appl. Phys. 2 42(7B) (2003) L866-L868.

[14] A. Momose, Recent Advances in X-ray Phase Imaging, Jap. J. of Appl. Phys. 44(9R) (2005) 6355.

[15] M. Muller, S. Bourbigot, S. Duquesne, R. Klein, G. Giannini, C. Lindsay, J. Vlassenbroeck, Investigation of the synergy in intumescent polyurethane by 3D computed tomography, Polym. Degrad. Stab. 98(9) (2013) 1638-1647.

[16] P. Müller, M. Morys, A. Sut, C. Jäger, B. Illerhaus, B. Schartel, Melamine poly(zinc phosphate) as flame retardant in epoxy resin: Decomposition pathways, molecular mechanisms and morphology of fire residues, Polym. Degrad. Stab. 130 (2016) 307-319.

[17] J.E.J. Staggs, Thermal conductivity estimates of intumescent chars by direct numerical simulation, Fire Saf. J. 45(4) (2010) 228-237.

[18] S. Brehme, B. Schartel, J. Goebbels, O. Fischer, D. Pospiech, Y. Bykov, M. Döring, Phosphorus polyester versus aluminium phosphinate in poly(butylene terephthalate) (PBT): Flame retardancy performance and mechanisms, Polym. Degrad. Stab. 96(5) (2011) 875884.

[19] P. Muller, B. Schartel, Melamine poly(metal phosphates) as flame retardant in epoxy resin: Performance, modes of action, and synergy, J. Appl. Polym. Sci. 133(24) (2016).

[20] H. Sturm, B. Schartel, A. Weiss, U. Braun, SEM/EDX: Advanced investigation of structured fire residues and residue formation, Polym. Test. 31(5) (2012) 606-619. 
[21] B. Hornberger, M.D. de Jonge, M. Feser, P. Holl, C. Holzner, C. Jacobsen, D. Legnini, D. Paterson, P. Rehak, L. Strueder, S. Vogt, Differential phase contrast with a segmented detector in a scanning X-ray microprobe, J. Synchrotron Radiat. 15 (2008) 355-362.

[22] S.A. McDonald, F. Marone, C. Hintermuller, G. Mikuljan, C. David, F. Pfeiffer, M. Stampanoni, Advanced phase-contrast imaging using a grating interferometer, J. Synchrotron Radiat. 16 (2009) 562-572.

[23] K. Medjoubi, N. Leclercq, F. Langlois, A. Buteau, S. Le, S. Poirier, P. Mercere, M.C. Sforna, C.M. Kewish, A. Somogyi, Development of fast, simultaneous and multi-technique scanning hard X-ray microscopy at Synchrotron Soleil, J. Synchrotron Radiat. 20 (2013) 293-299.

[24] F. Pfeiffer, T. Weitkamp, O. Bunk, C. David, Phase retrieval and differential phasecontrast imaging with low-brilliance X-ray sources, Nat. Phys. 2(4) (2006) 258-261.

[25] I. Zanette, M. Bech, A. Rack, G. Le Duc, P. Tafforeau, C. David, J. Mohr, F. Pfeiffer, T. Weitkamp, Trimodal low-dose X-ray tomography, Proc. Natl. Acad. Sci. U. S. A. 109(26) (2012) 10199-10204.

[26] H.J. Torben, B. Martin, B. Oliver, D. Tilman, D. Christian, F.l. Robert, F. Pfeiffer, Directional x-ray dark-field imaging, Phys. Med. Biol. 55(12) (2010) 3317.

[27] H. Wen, E.E. Bennett, M.M. Hegedus, S. Rapacchi, Fourier X-ray Scattering Radiography Yields Bone Structural Information, Radiology 251(3) (2009) 910-918.

[28] H.H. Wen, E.E. Bennett, R. Kopace, A.F. Stein, V. Pai, Single-shot x-ray differential phase-contrast and diffraction imaging using two-dimensional transmission gratings, Opt. Lett. 35(12) (2010) 1932-1934.

[29] L. Costa, G. Paganetto, G. Bertelli, G. Camino, Thermal-decomposition of Antimony Oxyhalide .1. Oxychlorides, J. Therm. Anal. Calorim. 36(3) (1990) 1141-1153.

[30] T. Felix, O.P. Pinto, A. Peres, J.M. Costa, C. Sayer, A.B. Morgan, P.H.H. Araujo, Comparison of bismuth trioxide and antimony trioxide as synergists with decabromodiphenyl ether in flame retardancy of high-impact polystyrene, J. Fire Sci. 30(6) (2012) 566-574.

[31] F. Gholamian, G. Nabiyouni, D. Ghanbari, R. Jalajerdi, A. Aminifazl, Synergistic Effect between Sb2O3 Nanostructure and Brominated Compound on the Flame Retardant Properties of the Polymeric Matrixes, High Temp. Mater.Proc. 32(2) (2013) 125-132.

[32] J. Green, Mechanisms for flame retardancy and smoke suppression - A review, J. Fire Sci. 14(6) (1996) 426-442.

[33] A.B. Morgan, J.W. Gilman, An overview of flame retardancy of polymeric materials: application, technology, and future directions, Fire Mater. 37(4) (2013) 259-279.

[34] K.A. Salmeia, J. Fage, S. Liang, S. Gaan, An overview of mode of action and analytical methods for evaluation of gas phase activities of flame retardants, Polymers 7(3) (2015) 504-526.

[35] A. Ramani, A.E. Dahoe, On the performance and mechanism of brominated and halogen free flame retardants in formulations of glass fibre reinforced poly(butylene terephthalate), Polym. Degrad. Stab. 104 (2014) 71-86.

[36] H. Sato, K. Kondo, S. Tsuge, H. Ohtani, N. Sato, Mechanisms of thermal degradation of a polyester flame-retarded with antimony oxide brominated polycarbonate studied by temperature-programmed analytical pyrolysis, Polym. Degrad. Stab. 62(1) (1998) 41-48.

[37] D. Ratna, Epoxy Composites: Impact Resistance and Flame Retardancy, Smithers Rapra Technology2007. 
[38] Underwriters Laboratory Inc. UL 94 standard for "tests for flammability of plastic materials for parts in devices and appliances" 333 Pfingsten Road, Northbrook, IL 60062 2096, 5th ed., 1996.

[39] Y. Arao, S. Nakamura, Y. Tomita, K. Takakuwa, T. Umemura, T. Tanaka, Improvement on fire retardancy of wood flour/polypropylene composites using various fire retardants, Polym. Degrad. Stab. 100 (2014) 79-85.

[40] Y. Wang, M.-J. Xu, B. Li, Synthesis of N-methyl triazine-ethylenediamine copolymer charring foaming agent and its enhancement on flame retardancy and water resistance for polypropylene composites, Polym. Degrad. Stab. 131 (2016) 20-29.

[41] X. Cao, N. Leyva, S.R. Anderson, B.C. Hancock, Use of prediction methods to estimate true density of active pharmaceutical ingredients, Int. J. Pharm. 355(1-2) (2008) 231-7.

[42] M. Kagias, Z.T. Wang, P. Villanueva-Perez, K. Jefimovs, M. Stampanoni, 2DOmnidirectional Hard-X-Ray Scattering Sensitivity in a Single Shot, Phys. Rev. Lett. 116(9) (2016).

[43] W. van Aarle, W.J. Palenstijn, J. Cant, E. Janssens, F. Bleichrodt, A. Dabravolski, J. De Beenhouwer, K. Joost Batenburg, J. Sijbers, Fast and flexible X-ray tomography using the ASTRA toolbox, Opt. Express 24(22) (2016) 25129-25147.

[44] X.W. Mu, B.H. Yuan, W.Z. Hu, S.L. Qiu, L. Song, Y. Hu, Flame retardant and antidripping properties of polylactic acid/poly(bis(phenoxy)phosphazene)/expandable graphite composite and its flame retardant mechanism, RSC Advances 5(93) (2015) 76068-76078. [45] M.-C. Despinasse, B. Schartel, Aryl phosphate-aryl phosphate synergy in flameretarded bisphenol A polycarbonate/acrylonitrile-butadiene-styrene, Thermochim. Acta 563 (2013) 51-61.

[46] S. Shaghaghi, A.R. Mahdavian, Flame-Retardancy Improvement of Novel StyreneMaleic Anhydride Based Copolymers, J. Polym. Res. 13(5) (2006) 413-419.

[47] A.P. Mouritz, A.G. Gibson, Fire Properties of Polymer Composite Materials, Springer Netherlands2007.

[48] L.A. Hollingbery, T.R. Hull, The fire retardant behaviour of huntite and hydromagnesite - A review, Polym. Degrad. Stab. 95(12) (2010) 2213-2225. 


\section{Graphical Abstract}

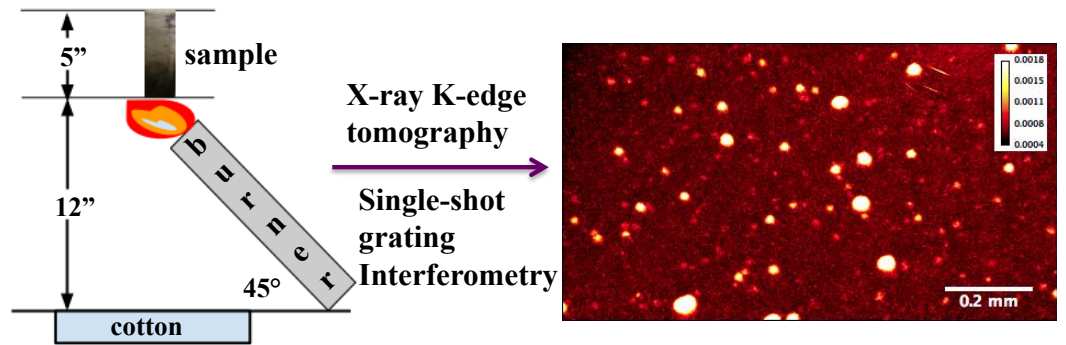

UL 94 burn test 